\title{
Influence of administration of mesenchymal stromal cell on pediatric oxygenator performance and inflammatory response
}

Takuya Maeda, MD, PhD, ${ }^{\text {a }}$ Casey M. Briggs, BS, ${ }^{\mathrm{a}, \mathrm{b}}$ Anushree Datar, MS, ${ }^{\mathrm{c}}$ Christine A. Brantner, PhD, ${ }^{\mathrm{d}}$ Patrick J. Hanley, PhD, ${ }^{\mathrm{c}, \mathrm{e}}$ Richard A. Jonas, MD, ${ }^{\mathrm{a}}$ and Nobuyuki Ishibashi, MD ${ }^{\mathrm{a}, \mathrm{e}}$

\section{ABSTRACT}

Objective: Mesenchymal stromal cells have important immunomodulatory and neuroprotective properties. The aim of this study was to evaluate the feasibility of mesenchymal stromal cell administration into a cardiopulmonary bypass (CPB) circuit, including a pediatric oxygenator, and to assess the immunomodulatory response of the circulating blood prime.

Methods: A bypass circuit with a pediatric oxygenator, including integral filter was primed with bank whole blood. Normal saline (control) or $120 \times 10^{6}$ mesenchymal stromal cells were injected into the venous reservoir after 80 minutes of perfusion. To assess oxygenator function, immune reaction, and cytokine/chemokine levels, the ex vivo circulation was maintained for 300 minutes after administration.

Results: There were no differences in flow rate, trans-oxygenator pressure gradient, blood oxygen, and carbon dioxide levels between control and cell delivery groups. No adhesion of mesenchymal stromal cells was observed on the filter mesh by scanning electron microscopy. Lymphocyte surface marker assay found no difference in the number of B cells, T cells, or natural killer cells between the 2 groups, indicating no immunogenicity of allogeneic mesenchymal stromal cells under ex vivo CPB conditions. CPB significantly changed the level of interleukin (IL) 4, IL-6, IL-8, IP-10, macrophage colony stimulating factor, macrophage inflammatory protein-1 $\beta$, monocyte chemoattractant protein-1, and IL-1 $\alpha$ over time. IL- 6 level was significantly increased after cell administration.

Conclusions: The administration of mesenchymal stromal cells does not interfere with oxygenator function. Allogeneic mesenchymal stromal cells show no immunogenicity, and increase plasma IL-6 level during ex vivo circulation. Further investigation is necessary to determine the effect of mesenchymal stromal cell delivery through CPB during pediatric cardiac surgery. (JTCVS Open 2021;5:99-107)

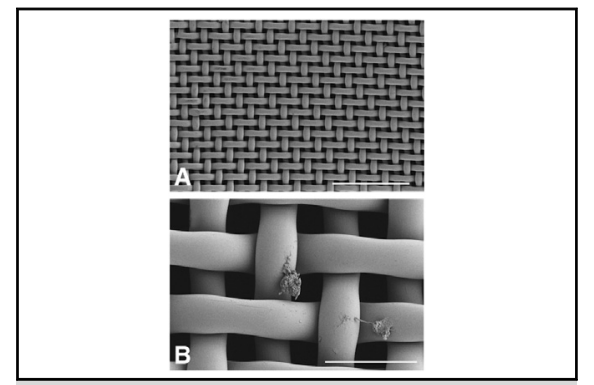

No adhesion of BM-MSCs was observed on the filter mesh after the injection into CPB.

CENTRAL MESSAGE

BM-MSC administration does

not interfere with pediatric

oxygenator function. There is no

immunogenicity of allogeneic

BM-MSCs during ex vivo CPB.

BM-MSC injection modulates

plasma IL-6 level.

\section{PERSPECTIVE}

BM-MSCs have immunomodulatory and neuroprotective properties. Our studies test CPB itself as a cell delivery system into the systemic circulation during pediatric cardiac surgery. The present study demonstrates the feasibility and significant translational potential of BM-MSC delivery through CPB in neonates and infants with congenital heart disease.

See Commentary on page 108.

\footnotetext{
From the ${ }^{\mathrm{a}}$ Center for Neuroscience Research, and Sheikh Zayed Institute for Pediatric Surgical Innovation, Children's National Heart Institute, and ${ }^{\mathrm{c}}$ Program for Cell Enhancement and Technologies for Immunotherapy, Division of Blood and Marrow Transplantation, Center for Cancer and Immunology Research, Chil-

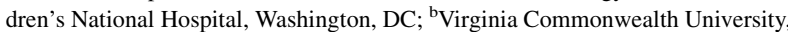
School of Medicine, Richmond, Va; and ${ }^{\mathrm{d}}$ GW Nanofabrication and Imaging Center and ${ }^{\mathrm{e}}$ Department of Pediatrics, Pharmacology and Physiology, The George Washington University School of Medicine and Health Science, Washington, DC. Supported by National Institutes of Health (NIH) grant R01HL139712 (to Dr Ishibashi), R01HL146670 (to Dr Ishibashi), and R33HL146394 (to Drs Ishibashi and Jones), and by the Office of the Assistant Secretary of Defense for Health Affairs through the Peer Reviewed Medical Research Program under Award No. W81XWH2010199 (to Dr Ishibashi). This work, including the immunoassay, was supported by the District of Columbia Intellectual and Developmental Disabilities Research Center (DC-IDDRC) Award U54HD090257 from the Eu-
}

nice Kennedy Shriver National Institute of Child Health and Human Development. Its contents are solely the responsibility of the authors and do not necessarily represent the official views of the DC-IDDRC or NIH.

Received for publication Feb 4, 2021; accepted for publication Feb 9, 2021; available ahead of print March 12, 2021.

Address for reprints: Nobuyuki Ishibashi, MD, Center for Neuroscience Research, and Sheikh Zayed Institute for Pediatric Surgical Innovation, Children's National Heart Institute, Children's National Hospital, 111 Michigan Ave, NW, Washington, DC 20010-2970 (E-mail: nishibas@ childrensnational.org).

2666-2736

Copyright (C) 2021 The Authors. Published by Elsevier Inc. on behalf of The American Association for Thoracic Surgery. This is an open access article under the CC BY-NC-ND license (http://creativecommons.org/licenses/by-nc-nd/4.0/).

https://doi.org/10.1016/j.xjon.2021.02.003 


\section{Abbreviations and Acronyms \\ $\mathrm{BM}-\mathrm{MSC}=$ bone marrow-derived mesenchymal stromal cell \\ CHD = congenital heart disease \\ $\mathrm{CPB}=$ cardiopulmonary bypass \\ ECMO = extracorporeal membrane oxygenator \\ GM-CSF $=$ macrophage colony stimulating factor \\ IL-6 = interleukin-6 \\ IP-10 $=$ interferon- $\gamma$-induced protein-10 \\ MCP-1 = monocyte chemoattractant protein-1 \\ MIP-1 $\beta=$ macrophage inflammatory protein- $1 \beta$ \\ SEM = scanning electron microscopy}

Video clip is available online.

Among the most important current challenges for children after neonatal cardiac surgery is to improve neurodevelopmental and behavioral outcomes. ${ }^{1,2}$ However, few treatment options are currently available. Bone marrow-derived mesenchymal stromal cells (BM-MSCs)-based therapies have been used in multiple clinical trials because of their important antiinflammatory, anti-apoptotic, and neuroprotective properties. ${ }^{3,4}$ Initial studies of application of BM-MSCs focused on the capacity of BM-MSCs to replace lost cells with socalled stem cells; however, over the past decade, the focus has shifted toward the ability of BM-MSCs to exert their effect via stimulation of endogenous trophic mechanisms for promoting regeneration through endogenous stem/progenitor cells. ${ }^{5}$ Indeed, we have previously demonstrated that BMMSC delivery through cardiopulmonary bypass (CPB) in a piglet model has the potential to mitigate the deleterious effect of CPB on neural stem/progenitor cells and to promote migration of neuroblasts toward the frontal cortex. ${ }^{6}$

CPB results in a systemic inflammatory response syndrome due to blood exposure to nonendothelial surfaces. ${ }^{7}$ In addition, our previous study using a neonatal piglet model has shown that $\mathrm{CPB}$ causes prolonged brainspecific inflammation. ${ }^{8}$ BM-MSCs are able to regulate both adaptive and innate immune responses, ${ }^{5,9}$ and have been widely applied in treatment for graft-versus-host disease and autoimmune disorders. ${ }^{3,10}$ These findings suggest that BM-MSC administration through CPB is potentially a highly effective approach to control the inflammatory response during pediatric cardiac surgery.

In our Phase 1 clinical trial, BM-MSCs must pass through the arterial filter integrated into a pediatric oxygenator before entering the patient's circulation. However the interaction of BM-MSCs with pediatric oxygenator performance is largely unknown. In addition, there is little information available regarding the direct immunomodulatory effect of BM-MSCs on the inflammatory response of circulating blood inside a CPB circuit. Therefore, the aim of the current study is to determine the interaction between BMMSC administration and the performance of a pediatric membrane oxygenator while assessing the effect of BMMSCs on the inflammatory response to $\mathrm{CPB}$ using an ex vivo model.

\section{MATERIAL AND METHODS \\ Experimental Model}

The ex vivo CPB circuit consists of a roller pump, a pediatric membrane oxygenator with integral arterial filter with a pore size of $32 \mu \mathrm{m}$ (CAPIOX FX05; Terumo Corp, Tokyo, Japan), X-coated tubing (Terumo Corp), heater/cooler unit and gas delivery system (Figure 1,A). The circuit was primed with $100 \mathrm{~mL}$ human red blood cells (Innovative Research Inc, Novi, Mich) and $5000 \mathrm{U}$ sodium heparin to simulate patient blood. Normal saline was used to adjust hematocrit levels between $30 \%$ and $40 \%$ (final priming volume; $175 \pm 32.4 \mathrm{~mL}$ ). At the beginning of ex vivo $\mathrm{CPB}, \mathrm{ABO}$-matched allogeneic whole blood (Innovative Research Inc) was administered to mimic exposure to an allogeneic blood prime. Pump flow rate was begun at $360 \mathrm{~mL} / \mathrm{min}$ blood flow and $37^{\circ} \mathrm{C}$ blood temperature to mimic the clinical case of a human infant with $3 \mathrm{~kg}$ body weight. Gas flow was maintained at $3 \mathrm{~L} / \mathrm{min}$ ( $95 \%$ oxygen and $5 \%$ carbon dioxide). The activated clotting time was maintained at $>400$ seconds during the perfusion simulation. After 80 minutes of perfusion, $10 \mathrm{~mL}$ normal saline either with $120 \times 10^{6} \mathrm{hu}-$ man BM-MSCs (MSC group, $\mathrm{n}=5$ ) or without cells (control, $\mathrm{n}=5$ ) were injected into the reservoir (Figure 1, $A$ ) to replicate the single injection protocol of our clinical trial. This dose was designed to assess the effect of the maximum target dose level in the clinical study $\left(40 \times 10^{6}\right.$ cells in infants weighing $3 \mathrm{~kg}$ ). CPB was maintained until 300 minutes after administration (380 minutes total). The purge line of the circuit was kept closed. The pressure lines across the oxygenator were used to assess the transoxygenator pressure gradient. The preoxygenator blood flow was also measured with an inline flow sensor (Transonic Systems Inc, Ithaca, NY). Blood samples were collected before the beginning of CPB and at 60 (20 minutes before injection), 110, 140, 260, and 380 minutes for blood gas analysis and assessment of immune responses.

To directly evaluate the interaction between BM-MSCs and the arterial filter, in an additional experiment cells were injected directly into the filter with a pore size of $32 \mu \mathrm{m}$ (CAPIOX CXAF02). After priming with heparinized normal saline ( $400 \mathrm{U}$ heparin $/ 100 \mathrm{~mL} 0.9 \%$ sodium chloride), 4 doses of BM-MSCs (control; no cell, $30 \times 10^{6}, 60 \times 10^{6}$, and $120 \times 10^{6}$ ) were injected into arterial filters (Figure $1, B$ ) to replicate target dose levels $\left(10 \times 10^{6}, 20 \times 10^{6}\right.$, and $40 \times 10^{6}$ cells $\left./ \mathrm{kg}\right)$ in infants with $3 \mathrm{~kg}$ body weight. Cells that passed through the filter were collected, and cell viabilities were evaluated with trypan blue exclusion method before and after injection.

Arterial filters were analyzed by scanning electron microscopy (SEM) to determine the extent of deposition of BM-MSCs on the filter surface. Arterial filters were rinsed 3 times with $0.1 \mathrm{M}$ phosphate buffer with $3.0 \%$ sucrose solution ( $\mathrm{pH} 7.4$ ) immediately after ex vivo CPB and after the direct injection test, and then rinsed 3 times with $0.9 \%$ sodium chloride. The filters were subsequently fixed by immersion at $4^{\circ} \mathrm{C}$ for 12 hours with $2 \%$ glutaraldehyde in $0.1 \mathrm{M}$ phosphate buffer with $3.0 \%$ sucrose solution ( $\mathrm{pH}$ 7.4). Imaging was performed from 5 different and distinct areas per filter using the Everhart-Thornley detector at $2 \mathrm{KV}$ and $9 \mathrm{~mm}$ WD.

Institutional review board approval was not required because all human blood products used in our studies were commercially available and manufactured for research purpose only. 

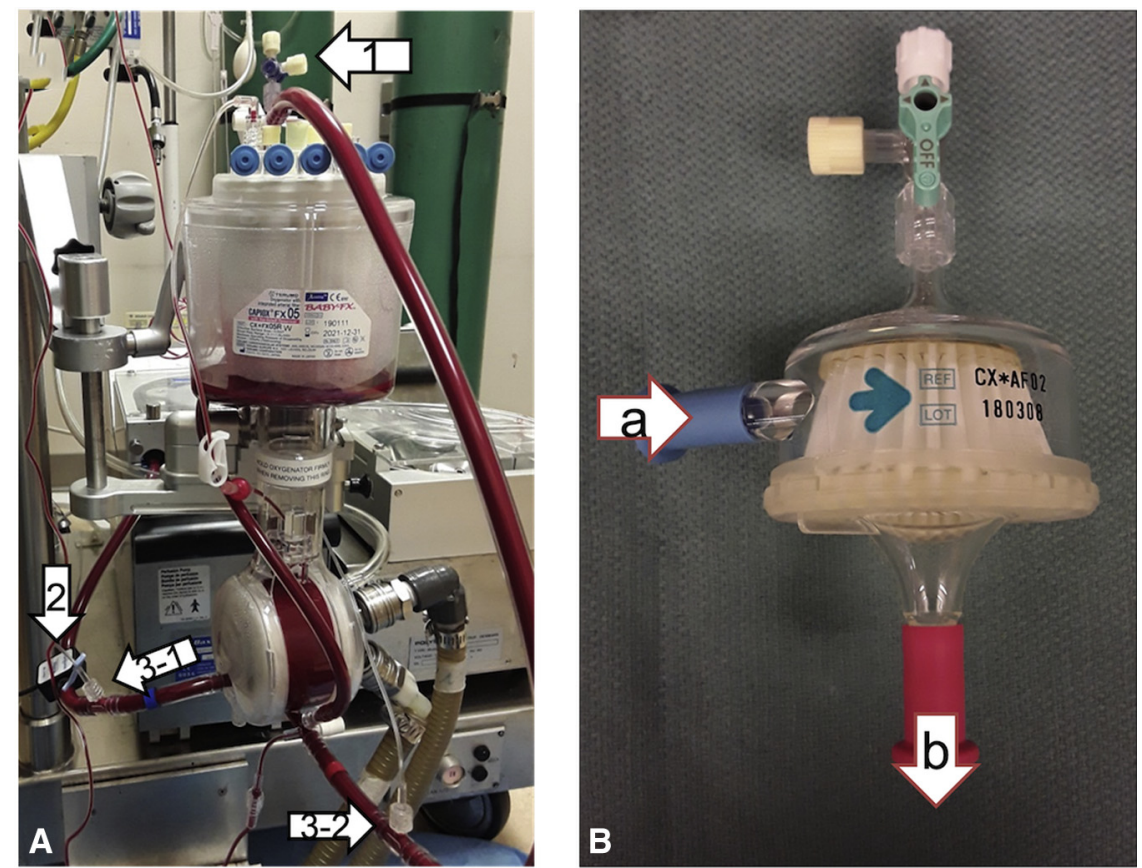

FIGURE 1. Schematic diagram of ex vivo circuit and direct injection test. A, The cardiopulmonary bypass circuit consists of a roller pump, a pediatric membrane oxygenator with an integral arterial filter, tubing, heater/cooler unit, and gas delivery system. The circuit is primed with $100 \mathrm{~mL}$ human red blood cells and sodium heparin. At the beginning of circulation, ABO-matched allogeneic whole blood is administered. After 80 minutes of perfusion, normal saline or bone marrow-derived mesenchymal stromal cells (BM-MSCs) are injected into a reservoir (arrow 1). The preoxygenator blood flow (arrow 2) and the pressures across the oxygenator (arrow 3-1 and 3-2) are measured to evaluate oxygenator performance. B, BM-MSCs are injected directly into the filter (arrow $a)$ and collected after an arterial filter (arrow $b$ ) to assess the effect of the filter on the cell number and viability of BM-MSCs.

\section{BM-MSC Development}

Human MSCs were manufactured from the bone marrow using the same methods that are used for clinical trials at the Good Manufacturing Practices clean room facility at Children's National Hospital. ${ }^{11}$ Bone marrow aspirated from normal donors was purchased from Lonza (Walkersville, Md), and expanded 2 passages in flasks to select out the MSCs. Then cells were expanded up to 6 total passages with the Quantum Cell Expansion system, which we described previously. ${ }^{6,11}$ Before infusion, BM-MSCs were tested according to the minimal criteria to define human BM-MSC published by the International Society of Cellular Therapy. ${ }^{12}$

\section{Immunogenicity and Cytokine Analysis}

To assess immune response to BM-MSC administration, subpopulations of leukocytes were evaluated using flow cytometry at baseline, the end of recirculation, and 12 hours after recirculation. Luminex assays (Procartaplex Multiplex Immunoassay; Thermo Fisher Scientific, Waltham, Mass) were also performed for twenty cytokine/chemokines including interferon- $\alpha$, interferon- $\gamma$, interleukin (IL)- $1 \alpha$, IL- $1 \beta$, IL-4, IL-6, IL-8, IL-10, IL-12p70, IL-13, IL-17A, tumor necrosis factor- $\alpha$, granulocyte macrophage colony stimulating factor (GM-CSF), macrophage inflammatory protein- $1 \alpha$, macrophage inflammatory protein- $1 \beta$ (MIP-1 $\beta$ ), monocyte chemoattractant protein-1 (MCP-1), interferon- $\gamma$ induced protein-10 (IP-10), E-selectin, P-selectin, and soluble intercellular adhesion molecule-1.

\section{Statistical Analysis}

The group $\times$ time interaction terms were evaluated with a 2-way analysis of variance. For a pairwise group comparison at each time point, Bonferroni post hoc testing or a 2-tailed, unpaired Student $t$ test was applied.
Statistical analysis was performed using the PRISM6 software package (GraphPad Software, Inc, La Jolla, Calif). $P$ values from $t$ test and 2-way analysis of variance were shown as raw $P$ value. Only for Bonferroni post hoc testing, adjusted $P$ values were applied.

\section{RESULTS \\ Pediatric Oxygenator Performance}

Blood flow rate and pressure gradient across the oxygenator were measured to assess the effect of BM-MSC administration on flow dynamics across the membrane oxygenator with integral arterial filter. There were no changes in flow rate during ex vivo CPB circulation in both control and BM-MSC groups (Figure 2, $A$ ). The transoxygenator pressure gradient decreased with time during 380 minutes of recirculation; however, there were no significant differences between the 2 groups (Figure 2, B). At the end of CPB, the transoxygenator pressure gradients in control and BMMSC group were 31.0 and $29.2 \mathrm{~mm} \mathrm{Hg}$, respectively. Consistent with these findings, we did not observe any differences in oxygen tension and carbon dioxide tension levels between control and BM-MSC groups up to 300 min after BM-MSC injection (Figure 2, $C$ and $D$ ). These findings confirm that BM-MSC administration into the $\mathrm{CPB}$ circuit does not interfere with pediatric oxygenator performance. 

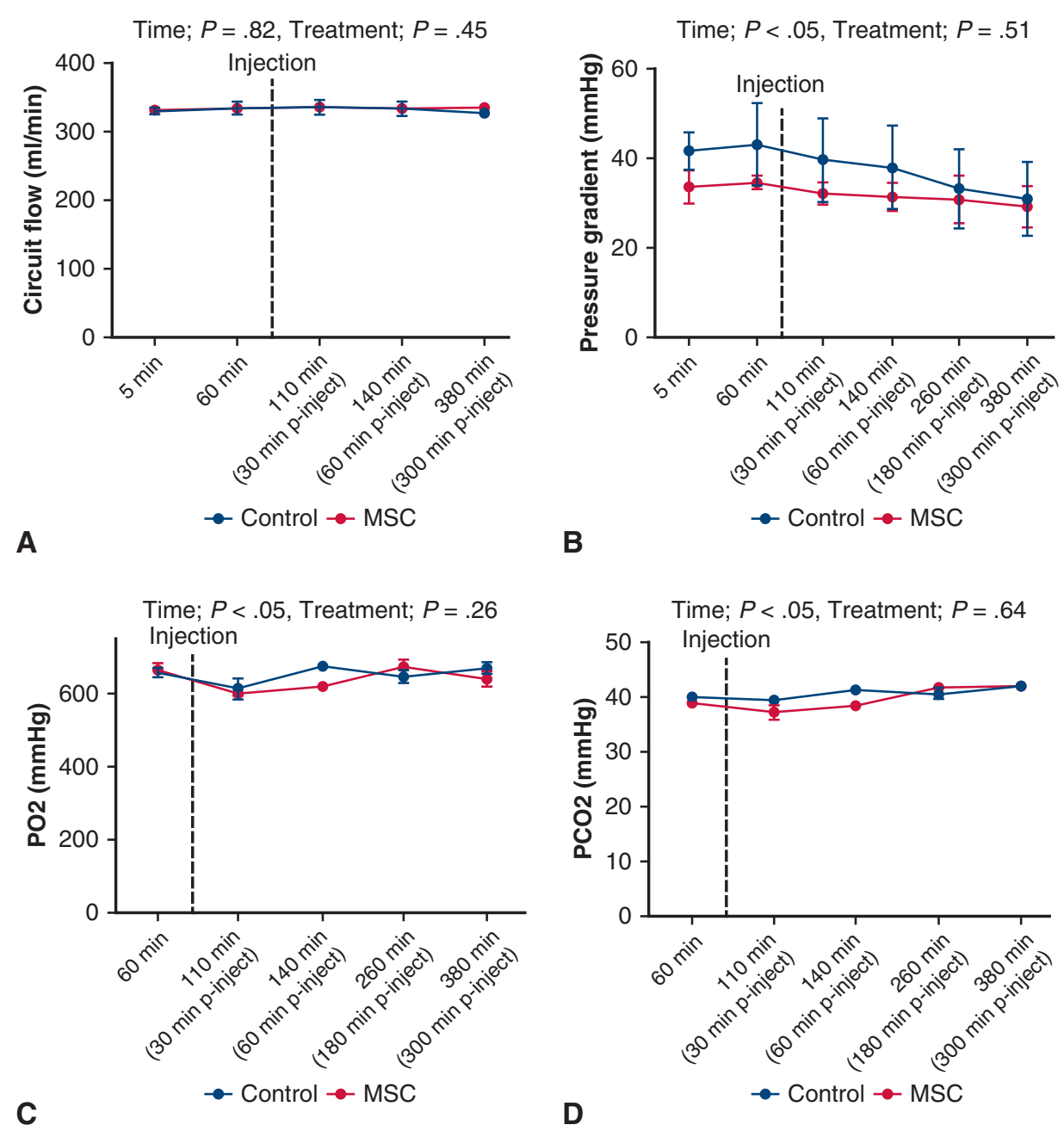

FIGURE 2. The administration of bone marrow-derived mesenchymal stromal cells (BM-MSCs) does not interfere with oxygenator performance during ex vivo cardiopulmonary bypass (CPB). A, There are no changes in blood flow rate during ex vivo CPB circulation in both control and BM-MSC groups. B, The transoxygenator pressure gradient decreases with time during 380 minutes of recirculation; however, there were no significant differences between the 2 groups. There is no difference in the (C) partial pressure of oxygen $(\mathrm{PO} 2)$ and (D) carbon dioxide (PCO2) level between control and BM-MSC groups up to 300 minutes after the injection. $P$ values are determined by 2 -way analysis of variance with Bonferroni comparisons. Data are shown as mean \pm standard error $(\mathrm{n}=5$ each). p-inject, Postinjection.

\section{Cell Adhesion on Arterial Filter Mesh}

To determine satisfactory passage of BM-MSCs through the arterial filter, filter meshes were assessed after ex vivo CPB. SEM showed only minor debris and no adhesion of BM-MSCs to the $32 \mu \mathrm{m}$-pore filter (Figure 3, $A$ and $B$ ). Direct injection tests were also performed to further assess interruption of BM-MSC delivery by the arterial filter (Figure 1, B). Consistent with the observation in ex vivo $\mathrm{CPB}$, there was no adhesion of BM-MSCs to the filter mesh after BM-MSC injection at 3 different doses $\left(30 \times 10^{6}, 60 \times 10^{6}\right.$, and $120 \times 10^{6}$ BM-MSCs $)$ (Figure 3, $C$ and $D$ ). Mean viability of BM-MSCs at the time of injection was $97.6 \%$. We also found that $80.2 \%$ cell viability was maintained after arterial filter passage. These findings suggest no important disturbance of cell viability and filter function by BM-MSC delivery through CPB.

\section{Immunogenicity Following Allogeneic BM-MSC Administration}

Allogeneic BM-MSCs may have cellular alloreactivity. To assess immune response after allogeneic BM-MSC administration, subpopulations of lymphocytes were evaluated by lymphocyte surface maker assay. BM-MSC administration into ex vivo CPB caused no significant alterations in the number of $\mathrm{B}$ cells, helper $\mathrm{T}$ cells, cytotoxic $\mathrm{T}$ cells, regulatory $\mathrm{T}$ cells, monocytes, and natural killer cells compared with control (Table 1), suggesting no immunogenicity of allogeneic BM-MSCs during ex vivo CPB. 

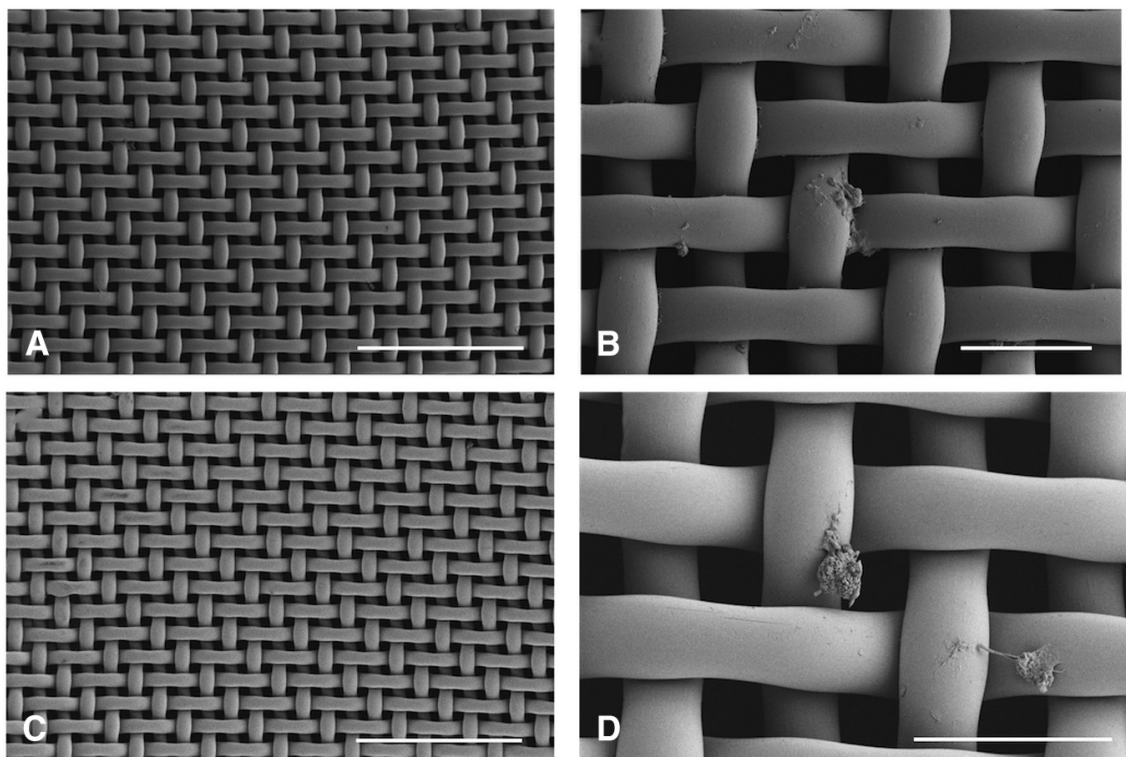

FIGURE 3. No adhesion of bone marrow-derived mesenchymal stromal cells (BM-MSCs) is observed on the filter mesh after ex vivo cardiopulmonary bypass (CPB), as well as direct injection test. Scanning electron microscopy shows only minor debris and no adhesion of BM-MSCs to the $32 \mu \mathrm{m}-$ pore arterial filter after both the ex vivo CPB (A and B) and the direct injection test using $120 \times 10^{6}$ cells (C and D). Magnified image shows some adherent debris (B and D). Scale bar is $500 \mu \mathrm{m}$ (A and C) or $100 \mu \mathrm{m}$ (B and D).

\section{Cytokine/Chemokine Levels}

A total of 20 cytokines, chemokines, and growth factors were evaluated to assess the effect of BM-MSCs on CPBinduced systemic inflammatory response. There were significant declines in the levels of IL-4, GM-CSF, IP-10 and MIP-1 $\beta$ over time (Figure 4). IL-4 and GM-CSF have significant anti-inflammatory properties. ${ }^{13,14}$ We observed no differences in those cytokine and chemokine levels between the control and BM-MSC groups (Figure 4). IL-8, MCP-1, and IL- $1 \alpha$ are well known as proinflammatory cytokines and chemokines. ${ }^{15,16}$ Our assays revealed significant increases in the level of IL-8, MCP-1, IL- $1 \alpha$, and IL-6 during ex vivo CPB (Figure 5). Although there were no differences in the levels of IL-8, MCP-1, and IL- $1 \alpha$ between the control and BM-MSC groups, we observed significant increase in IL-6 level after BM-MSC administration compared with control (Figure 5, $D$ and Video 1).

\section{DISCUSSION}

This is the first study to evaluate the feasibility of BMMSC delivery through the pediatric CPB circuit. The present study using an ex-vivo CPB model has shown that BM-MSC administration does not interfere with pediatric oxygenator performance. SEM assessment reveals no cell adherence on the filter mesh after BM-MSC delivery. Furthermore, our lymphocyte surface maker assay has demonstrated no immunogenicity of allogeneic BMMSCs under CPB. Finally, our results indicate a significant increase of plasma IL-6 level by BM-MSC administration.
Among the unique features of our studies is testing CPB itself as a cell delivery system into the systemic circulation during pediatric cardiac surgery. Meta-analyses of various clinical trials comprising a total of 2625 and 2037 patients have confirmed the long-term safety specifically of intra-arterial delivery at a wide range of BM-MSC doses with zero reports of serious events, such as embolic events leading to obstruction/stenosis of coronary arteries or myocardial ischemia. ${ }^{17,18}$ Nevertheless, the method of administration of BM-MSCs in this study and in a planned clinical trial requires passage of the cells through the arterial filter that is integrated with the pediatric oxygenator. The pore size of the arterial filter integrated with the pediatric CPB system employed in this study is $32 \mu \mathrm{m}$. Although the average diameter of human BM-MSCs is estimated to be between 10 and $25 \mu \mathrm{m},{ }^{19,20}$ the plastic adherent characteristics of BM-MSCs might affect either filter function or cell viability after passing through the filter mesh. ${ }^{12}$ A majority of current pediatric oxygenators integrate the arterial filter. Therefore disturbance of the filter function by BM-MSCs potentially alters gas exchange function due to excessive turbulence and/or pressure effects around the hollow fibers in the oxygenator. Previous studies using an extracorporeal membrane oxygenator (ECMO) showed loss of injected BM-MSCs, cell adhesion to the oxygenator, and rapid decline in oxygenator function after ex vivo ECMO circulation. ${ }^{21,22}$ However the Quadrox (Maquet Cardiopulmonary $\mathrm{GmbH}$, Rastatt, Germany) oxygenator used in those studies differs from standard CPB microporous oxygenators in both the polymer employed for 
TABLE 1. Lymphocyte count during ex vivo cardiopulmonary bypass $(\mathrm{CPB})^{*}$

\begin{tabular}{|c|c|c|c|}
\hline Lymphocyte & Control $(n=4)$ & $\operatorname{MSC}(n=4)$ & $\boldsymbol{P}$ value $\dagger$ \\
\hline \multicolumn{4}{|c|}{$\mathrm{CD} 3+\mathrm{T}$ cells $(/ \mu \mathrm{L})$} \\
\hline Baseline & $533.3 \pm 344.6$ & $263.4 \pm 229.9$ & .24 \\
\hline End of $\mathrm{CPB}$ & $135.6 \pm 106.0$ & $118.0 \pm 61.9$ & .78 \\
\hline $12 \mathrm{~h}$ after $\mathrm{CPB}$ & $98.7 \pm 83.2$ & $88.1 \pm 58.4$ & .84 \\
\hline \multicolumn{4}{|c|}{$\mathrm{CD} 3+\mathrm{CD} 4+$ helper $\mathrm{T}$ cells $(/ \mu \mathrm{L})$} \\
\hline Baseline & $332.3 \pm 237.8$ & $201.5 \pm 144.1$ & .38 \\
\hline End of CPB & $98.0 \pm 76.0$ & $84.2 \pm 38.5$ & .76 \\
\hline $12 \mathrm{~h}$ after $\mathrm{CPB}$ & $71.0 \pm 57.7$ & $64.5 \pm 37.7$ & .86 \\
\hline \multicolumn{4}{|c|}{$\mathrm{CD} 3+\mathrm{CD} 8+$ cytotoxic $\mathrm{T}$ cells $(/ \mu \mathrm{L})$} \\
\hline Baseline & $146.7 \pm 132.7$ & $67.5 \pm 69.4$ & .33 \\
\hline End of CPB & $27.9 \pm 25.9$ & $22.9 \pm 13.8$ & .74 \\
\hline $12 \mathrm{~h}$ after $\mathrm{CPB}$ & $22.2 \pm 20.8$ & $17.5 \pm 13.2$ & .72 \\
\hline \multicolumn{4}{|c|}{$\mathrm{CD} 127-\mathrm{CD} 25+\mathrm{CD} 4+$ regulatory $\mathrm{T}$ cells $(/ \mu \mathrm{L})$} \\
\hline Baseline & $39.2 \pm 37.0$ & $37.6 \pm 37.8$ & .95 \\
\hline End of CPB & $4.5 \pm 4.5$ & $11.5 \pm 19.1$ & .50 \\
\hline $12 \mathrm{~h}$ after $\mathrm{CPB}$ & $7.3 \pm 11.7$ & $10.1 \pm 13.5$ & .76 \\
\hline \multicolumn{4}{|c|}{$\mathrm{CD} 19+\mathrm{B}$ cells $(/ \mu \mathrm{L})$} \\
\hline Baseline & $262.5 \pm 194.1$ & $211.0 \pm 203.3$ & .73 \\
\hline End of CPB & $62.6 \pm 50.6$ & $56.7 \pm 46.2$ & .87 \\
\hline $12 \mathrm{~h}$ after $\mathrm{CPB}$ & $42.5 \pm 37.3$ & $44.7 \pm 33.7$ & .93 \\
\hline \multicolumn{4}{|c|}{ CD14 + monocytes $(/ \mu \mathrm{L})$} \\
\hline Baseline & $110.9 \pm 105.1$ & $94.3 \pm 129.2$ & .85 \\
\hline End of CPB & $38.1 \pm 57.2$ & $12.7 \pm 15.1$ & .42 \\
\hline $12 \mathrm{~h}$ after $\mathrm{CPB}$ & $34.0 \pm 56.1$ & $10.8 \pm 10.4$ & .45 \\
\hline \multicolumn{4}{|c|}{ CD56 + natural killer cells $(/ \mu \mathrm{L})$} \\
\hline Baseline & $7.9 \pm 3.5$ & $2.8 \pm 2.8$ & .06 \\
\hline End of CPB & $4.5 \pm 5.7$ & $4.9 \pm 5.5$ & .93 \\
\hline $12 \mathrm{~h}$ after $\mathrm{CPB}$ & $4.4 \pm 6.9$ & $5.2 \pm 6.5$ & .87 \\
\hline
\end{tabular}

Values are presented as mean \pm standard deviation. MSC, Mesenchymal stromal cell, $C D$, cluster of differentiation. *The administration of bone marrow-derived mesenchymal stromal cells into ex vivo CPB causes no significant alterations in the subpopulations of lymphocytes compared with control. $\dagger P$ values determined by unpaired $t$ test.

microfiber construction as well as the weave of the fibers. Consistent with clinical application during pediatric cardiac surgery, our studies also maintained a higher activated clotting time compared to ECMO. ${ }^{22}$ BM-MSCs potentially activate the coagulation system via tissue factor which can be prevented by anticoagulant agents. ${ }^{23,24}$ Thus it is possible that heparinization level is an important factor for the complex interaction between BM-MSCs and a membrane oxygenator. The current study using a standard CPB microporous membrane oxygenator demonstrated no alterations in blood flow, transoxygenator pressure gradient and oxygenation function up to 5 hours after BM-MSC administration. Furthermore our SEM studies demonstrated no adherence of BM-MSCs on the surface of the arterial filter after 2 different methods of cell administration. Finally, the present study confirmed maintained viability of BM-MSCs after passage through the arterial filter. Altogether, our results indicate the feasibility and significant translational potential of BM-MSC delivery through CPB.
CPB results in a systemic inflammatory response due to blood exposure to nonendothelial surfaces, such as the artificial oxygenator, tubing, and cannulas. ${ }^{7}$ The present study confirmed that CPB circulation with allogeneic red blood cell transfusion changed the plasma levels of several cytokine/chemokines and growth factors. Proinflammatory cytokines and chemokines including IL-8, MCP-1, and IL- $1 \alpha$ were significantly increased over time. Conversely, IL-4 and GM-CSF, which are known to have antiinflammatory properties, were reduced. ${ }^{13,14}$ We also observed decreases in IP-10 and MIP- $1 \beta$ levels during ex vivo $\mathrm{CPB}$. Although their biological functions are still unclear, IP-10 induces chemotaxis and cell growth, whereas MIP-1 stimulates chemotaxis, degranulation, and phagocytosis under inflammatory conditions. ${ }^{25,26}$ BM-MSCs directly injected into the ex vivo CPB significantly increased circulating plasma IL- 6 level. The properties of IL-6 are highly complex and multi-factorial, including both anti- and pro-inflammatory effects. ${ }^{27}$ Notably, the IL-6 produced by BM-MSCs has been reported to polarize monocytes toward anti-inflammatory M2 macrophages. $^{28,29}$ The polarizing effect on M2 macrophages is closely linked with the emergence of regulatory $\mathrm{T}$ cells, which are involved in immunosuppression. ${ }^{30}$ In addition BM-MSC derived IL-6 has been shown to dampen the respiratory burst in neutrophils, which produces reactive oxygen species, and to delay the spontaneous apoptosis of activated neutrophils. ${ }^{31}$ The repeated passage of blood through the $\mathrm{CPB}$ circuit can continuously trigger the activation of polymorphonuclear leukocytes, mainly neutrophils. $^{32}$ Because the IL-6 level in the MSC group increased over time, we hypothesize that BM-MSCs react to continuous activation of neutrophils and release IL-6, thereby causing the continuous increase. However it is still possible that donor polymorphonuclear leukocytes were a major source of IL-6 during ex vivo CPB. Thus further studies will be required to understand the unique alteration of IL-6 level observed in the present study. It is also necessary to determine the effects of BM-MSCs on the systemic inflammatory response and the contribution of IL-6 to multiorgan function after pediatric cardiac surgery.

Allogeneic BM-MSCs may have cellular and humoral alloreactivity. ${ }^{6}$ The present study; however, demonstrated that allogenic BM-MSC infusion did not change the subpopulation of lymphocytes immediately following CPB and 12 hours after CPB. BM-MSCs show low expression of major histocompatibility class II antigen. ${ }^{33}$ BM-MSCs also have important immunomodulatory properties, including a suppressive effect on T- and B-cell proliferation, suppression of natural killer cell function, and modulation of the secretory profile of dendritic cells and macrophages. ${ }^{33,34}$ These properties are considered to contribute to the low immunogenicity of BM-MSCs after allogeneic transplantation. 

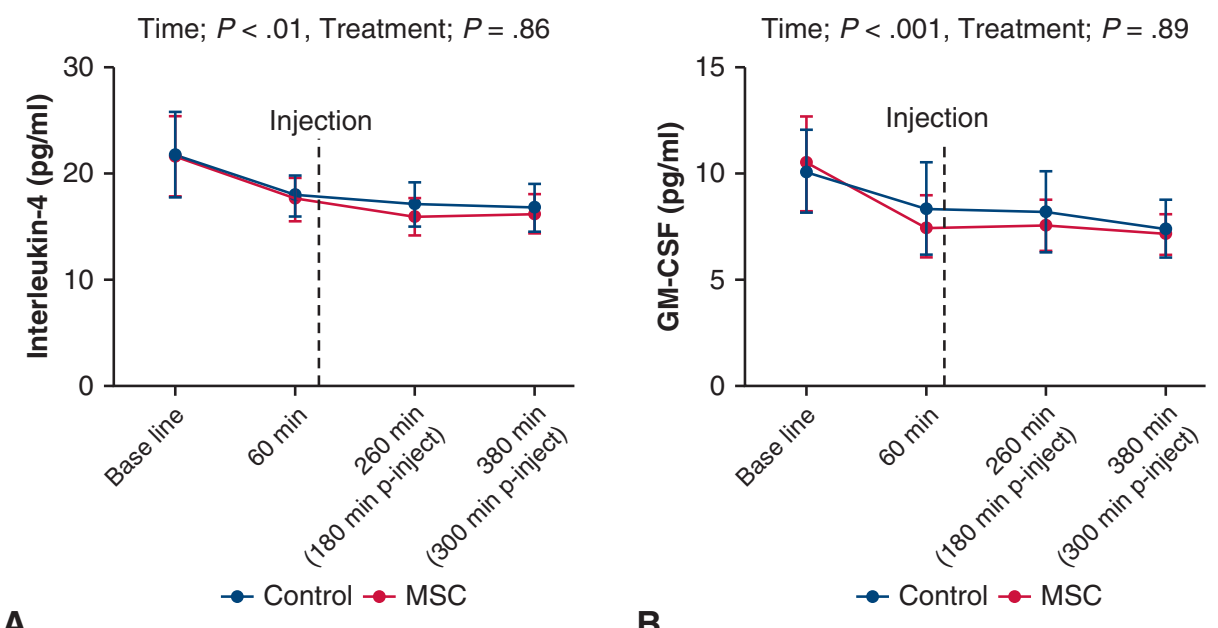

A

B
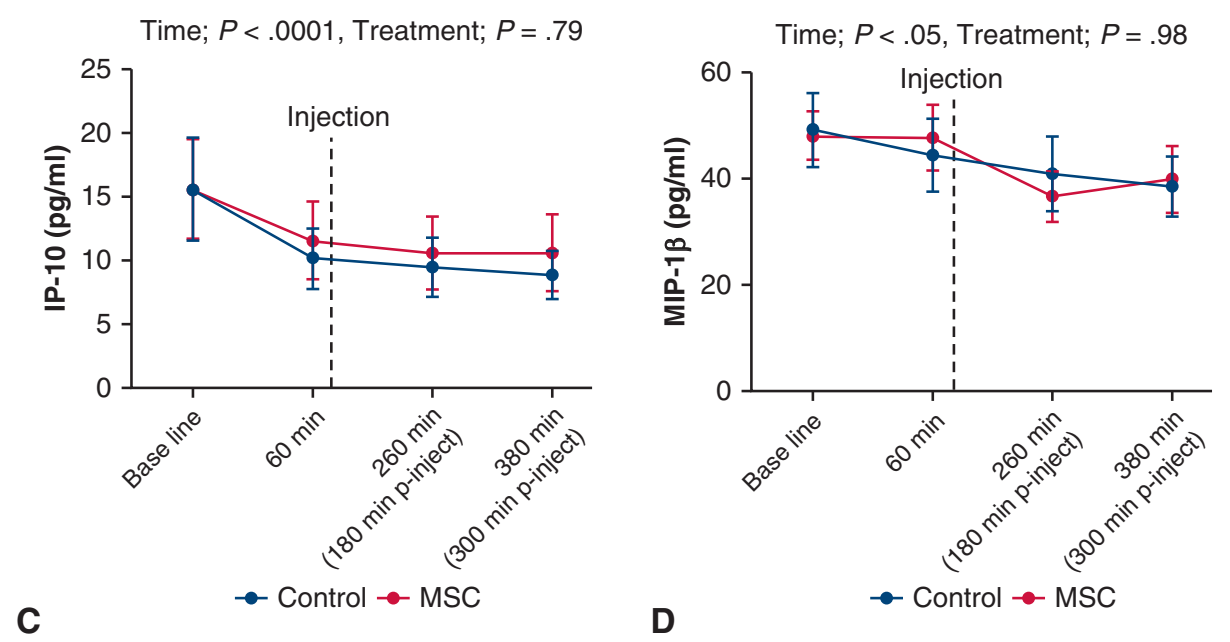

FIGURE 4. Ex vivo cardiopulmonary bypass $(\mathrm{CPB})$ changes several cytokine and chemokine levels. There are significant declines in the levels of interleukin-4 (A), granulocyte macrophage colony stimulating factor (GM-CSF) (B), interferon- $\gamma$-induced protein-10 (IP-10) (C), and macrophage inflammatory protein-1 $\beta(M I P-1 \beta)(\mathrm{D})$ over time. There are no differences in those cytokine and chemokine levels between the control and mesenchymal stromal cell (BM-MSC) groups. $P$ values are determined by 2-way analysis of variance with Bonferroni comparisons. Data are shown as mean \pm standard error $(\mathrm{n}=5$ each). p-inject, Postinjection.

Our studies using an ex vivo CPB circuit include obvious limitations. Several studies have demonstrated that BM-MSCs polarize lymphocytes, including $\mathrm{T}$ cells and monocytes toward a regulatory phenotype, and generate regulatory $\mathrm{T}$ cells. ${ }^{3,35}$ In the present study, we did not observe cellular reactions by BM-MSCs during ex vivo circulation. There are no interactions of both circulating blood and delivered BM-MSCs with endothelium and organs that are also responsible for immune reactions, including lymph nodes, thymus, and spleen. In addition, because of technical challenges, cell viability of delivered BM-MSCs was not continuously monitored over the course of the experiment although it was $97.6 \%$ at the time of injection. A lack of interaction between important tissues and/or reduced cell viability during the experiment may have contributed to this result. Mechanisms underlying immune response during CPB are highly complex and multicellular events. Comparing immune and inflammatory responses between ex vivo circulation and in vivo preclinical and clinical studies will assist in our understanding of the effect of BM-MSCs on complex immune reactions and alterations in T-cell function after CPB.

Among the most important current challenges for children with congenital heart disease (CHD) is to improve neurodevelopmental and behavioral outcomes. We have recently established a Phase 1 clinical trial to assess the safety and feasibility of BM-MSC delivery through CPB in neonates and young infants with CHD. Ultimately, it is to be hoped that the proposed cell-based therapeutic approach during neonatal cardiac surgery can contribute to improvement of lifelong neurobehavioral problems in populations with CHD. 

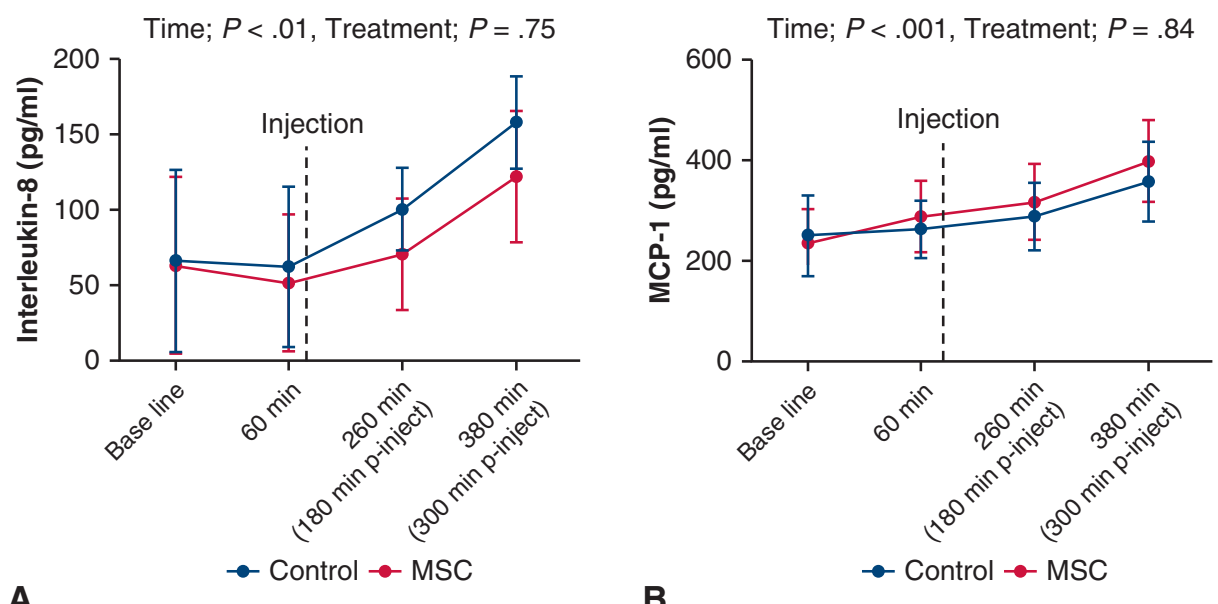

A

B

Time; $P<.01$, Treatment; $P<.05$
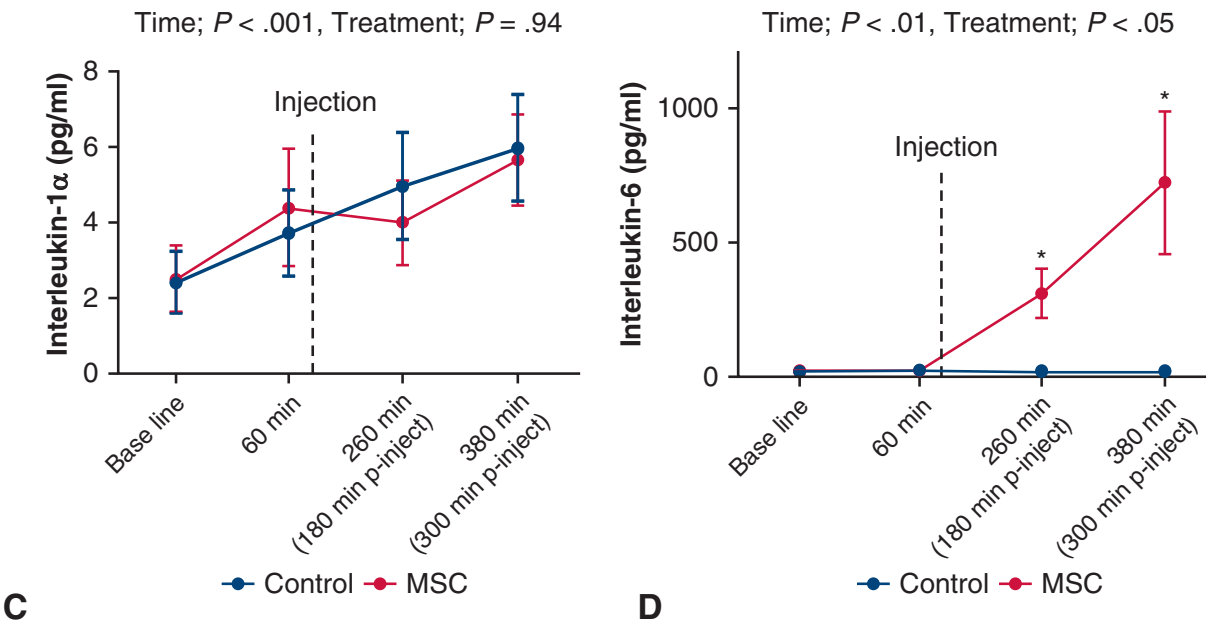

FIGURE 5. Ex vivo cardiopulmonary bypass (CPB) modulates plasma cytokine/chemokine levels. The administration of bone marrow-derived mesenchymal stromal cells (BM-MSCs) increases interleukin-6. The ex vivo CPB significantly increases some proinflammatory cytokine and chemokines including interleukin-8 (A), monocyte chemoattractant protein 1 (MCP-1) (B), and interleukin-1 $\alpha$ (C) over time. D, The plasma interleukin-6 level is significantly increased after BM-MSC administration compared with control. $P$ values for the group $\times$ time interaction terms are determined by 2 -way analysis of variance. Group comparisons at each time points were evaluated with unpaired Student $t$ test. $* P<.05$ versus control by unpaired Student $t$ test. Data are shown as mean \pm standard error $(\mathrm{n}=5$ each). p-inject, Postinjection.

\section{CONCLUSIONS}

The present study demonstrates the feasibility and significant translational potential of BM-MSC delivery through CPB. Future investigation using an in vivo model is necessary for further understanding of the effect of BM-MSC administration during pediatric cardiac surgery.

\section{Conflict of Interest Statement}

Dr Hanley is a cofounder and on the board of directors of Mana Therapeutics and serves on the scientific advisory board of Cellevolve. All other authors reported no conflicts of interest.

The Journal policy requires editors and reviewers to disclose conflicts of interest and to decline handling or reviewing manuscripts for which they may have a conflict of interest. The editors and reviewers of this article have no conflicts of interest.

The authors thank Ms Karuna Panchapakesan, (Center for Genetic Medicine Research at Children's National Hospital) for assistance with cytokine and chemokine analysis, Mr Robert Ulrey (Center for Cancer and Immunology Research at Children's National Hospital) for bone marrow-derived mesenchymal stromal cell development and analysis of cell viability, and Dr Christopher Lazarski (Center for Cancer and Immunology Research at Children's National Hospital) for leukocyte analysis with flow cytometry. The authors also thank Ms Nimisha Vasandani and Dr Mobolanle Ayodeji for critically reading this manuscript, as well as the Foglia and Hill families who have the vision and generosity to support the Cardiac Surgery Research Laboratory at Children's National Hospital. 
No adhesion of bone marrow-derived mesenchymal stromal cells (BM-MSCs) was observed on the filter mesh after ex-vivo cardiopulmonary bypass (CPB).
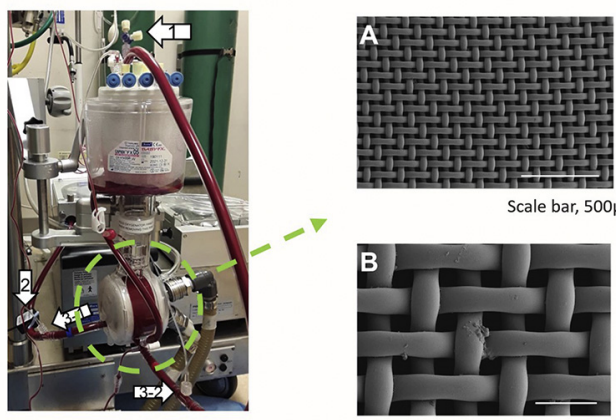

Scale bar, $500 \mu \mathrm{m}$

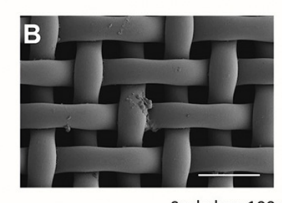

Scale bar, $100 \mu \mathrm{m}$

Q. Children's National

VIDEO 1. Human bone marrow-derived mesenchymal stromal cells (BMMSCs) injected into an ex vivo pediatric cardiopulmonary bypass (CPB) circuit did not interfere with oxygenator function. BM-MSCs significantly increased circulating plasma interleukin-6 level. Video available at: https:// www.jtcvs.org/article/S2666-2736(21)00023-1/fulltext.

\section{References}

1. Marino BS, Lipkin PH, Newburger JW, Peacock G, Gerdes M, Gaynor JW, et al. Neurodevelopmental outcomes in children with congenital heart disease: evaluation and management: a scientific statement from the American Heart Association. Circulation. 2012;126:1143-72.

2. Gaynor JW, Stopp C, Wypij D, Andropoulos DB, Atallah J, Atz AM, et al. Neurodevelopmental outcomes after cardiac surgery in infancy. Pediatrics. 2015;135: 816-25.

3. Bernardo ME, Fibbe WE. Mesenchymal stromal cells: sensors and switchers of inflammation. Cell Stem Cell. 2013;13:392-402.

4. Lee JS, Hong JM, Moon GJ, Lee PH, Ahn YH, Bang OY, et al. A long-term follow-up study of intravenous autologous mesenchymal stem cell transplantation in patients with ischemic stroke. Stem Cells. 2010;28:1099-106.

5. van Velthoven CT, Kavelaars A, Heijnen CJ. Mesenchymal stem cells as a treatment for neonatal ischemic brain damage. Pediatr Res. 2012;71:7.

6. Maeda T, Sarkislali K, Leonetti C, Kapani N, Dhari Z, Al Haj I, et al. Impact of mesenchymal stromal cell delivery through cardiopulmonary bypass on postnatal neurogenesis. Ann Thorac Surg. 2020;109:1274-81.

7. Levy JH, Tanaka KA. Inflammatory response to cardiopulmonary bypass. Ann Thorac Surg. 2003;75:S715-20.

8. Korotcova L, Kumar S, Agematsu K, Morton PD, Jonas RA, Ishibashi N. Prolonged white matter inflammation after cardiopulmonary bypass and circulatory arrest in a juvenile porcine model. Ann Thorac Surg. 2015;100:1030-7.

9. Keating A. Mesenchymal stromal cells: new directions. Cell Stem Cell. 2012;10: 709-16.

10. Le Blanc K, Frassoni F, Ball L, Locatelli F, Roelofs H, Lewis I, et al. Mesenchymal stem cells for treatment of steroid-resistant, severe, acute graft-versushost disease: a phase II study. Lancet. 2008;371:1579-86.

11. Hanley PJ, Mei Z, Durett AG, Mda G, Cabreira-Hansen M, Klis M, Li W, et al. Efficient manufacturing of therapeutic mesenchymal stromal cells with the use of the Quantum Cell Expansion System. Cytotherapy. 2014;16:1048-58.

12. Dominici M, Le Blanc K, Mueller I, Slaper-Cortenbach I, Marini F, Krause D, et al. Minimal criteria for defining multipotent mesenchymal stromal cells. The International Society for Cellular Therapy position statement. Cytotherapy. 2006:8:315-7.

13. Opal SM, DePalo VA. Anti-inflammatory cytokines. Chest. 2000;117:1162-72.

14. Becher B, Tugues S, Greter M. GM-CSF: from growth factor to central mediator of tissue inflammation. Immunity. 2016;45:963-73.
15. Mukaida N, Harada A, Matsushima K. Interleukin-8 (IL-8) and monocyte chemotactic and activating factor (MCAF/MCP-1), chemokines essentially involved in inflammatory and immune reactions. Cytokine Growth Factor Rev. 1998;9:9-23.

16. Di Paolo NC, Shayakhmetov DM. Interleukin 1 alpha and the inflammatory process. Nat Immunol. 2016;17:906-13.

17. Jeevanantham V, Butler M, Saad A, Abdel-Latif A, Zuba-Surma EK, Dawn B. Adult bone marrow cell therapy improves survival and induces long-term improvement in cardiac parameters: a systematic review and meta-analysis. Circulation. 2012;126:551-68.

18. de Jong R, Houtgraaf JH, Samiei S, Boersma E, Duckers HJ. Intracoronary stem cell infusion after acute myocardial infarction: a meta-analysis and update on clinical trials. Circ Cardiovasc Interv. 2014;7:156-67.

19. Ge J, Guo L, Wang S, Zhang Y, Cai T, Zhao RC, et al. The size of mesenchymal stem cells is a significant cause of vascular obstructions and stroke. Stem Cell Rev Rep. 2014;10:295-303.

20. Bartosh TJ, Ylostalo JH, Mohammadipoor A, Bazhanov N, Coble K, Claypool K, et al. Aggregation of human mesenchymal stromal cells (MSCs) into 3D spheroids enhances their anti-inflammatory properties. Proc Natl Acad Sci U S A. 2010;107:13724-9.

21. Cho HJ, Hong H, Kim DW, Lee KS, Han HS, Kim GH, et al. Viability of mesenchymal stem cells in an ex vivo circulation system. ASAIO J. 2020; 66:433-40.

22. Millar JE, von Bahr V, Malfertheiner MV, Ki KK, Redd MA, Bartnikowski N et al. Administration of mesenchymal stem cells during ECMO results in a rapid decline in oxygenator performance. Thorax. 2019;74:194-6.

23. Coppin L, Najimi M, Bodart J, Rouchon MS, van der Smissen P, Eeckhoudt S, et al. Clinical protocol to prevent thrombogenic effect of liver-derived mesenchymal cells for cell-based therapies. Cells. 2019;8:846.

24. Liao L, Shi B, Chang H, Su X, Zhang L, Bi C, et al. Heparin improves BMSC cell therapy: anticoagulant treatment by heparin improves the safety and therapeutic effect of bone marrow-derived mesenchymal stem cell cytotherapy. Theranostics. 2017;7:106-16.

25. Wang Z, Wu T, Ma M, Zhang Z, Fu Y, Liu J, et al. Elevated interferon-gammainduced protein 10 and its receptor CXCR3 impair NK cell function during HIV infection. J Leukoc Biol. 2017;102:163-70.

26. Maurer M, von Stebut E. Macrophage inflammatory protein-1. Int J Biochem Cel Biol. 2004;36:1882-6.

27. Scheller J, Chalaris A, Schmidt-Arras D, Rose-John S. The pro- and antiinflammatory properties of the cytokine interleukin-6. Biochim Biophys Acta. 2011;1813:878-88.

28. Eggenhofer E, Hoogduijn MJ. Mesenchymal stem cell-educated macrophages. Transplant Res. 2012;1:12.

29. Ghannam S, Pene J, Moquet-Torcy G, Jorgensen C, Yssel H. Mesenchymal stem cells inhibit human Th17 cell differentiation and function and induce a $\mathrm{T}$ regulatory cell phenotype. J Immunol. 2010;185:302-12.

30. Melief SM, Schrama E, Brugman MH, Tiemessen MM, Hoogduijn MJ, Fibbe WE, et al. Multipotent stromal cells induce human regulatory T cells through a novel pathway involving skewing of monocytes toward antiinflammatory macrophages. Stem Cells. 2013;31:1980-91.

31. Raffaghello L, Bianchi G, Bertolotto M, Montecucco F, Busca A, Dallegri F, et al Human mesenchymal stem cells inhibit neutrophil apoptosis: a model for neutrophil preservation in the bone marrow niche. Stem Cells. 2008;26:151-62.

32. Zakkar M, Guida G, Suleiman MS, Angelini GD. Cardiopulmonary bypass and oxidative stress. Oxid Med Cell Longev. 2015;2015:189863.

33. Le Blanc K, Pittenger M. Mesenchymal stem cells: progress toward promise. $C y$ totherapy. 2005;7:36-45.

34. Griffin MD, Ritter T, Mahon BP. Immunological aspects of allogeneic mesenchymal stem cell therapies. Hum Gene Ther. 2010;21:1641-55.

35. Uccelli A, Moretta L, Pistoia V. Mesenchymal stem cells in health and disease. Nat Rev Immunol. 2008;8:726-36.

Key Words: cardiopulmonary bypass, congenital heart disease, cerebral protection, cell transplantation, mesenchymal stromal cells 